\title{
Êxitos e limites na prevenção da violência: estudo de caso de nove experiências brasileiras
}

\author{
Success and limitations in the prevention \\ of violence; a case study of nine Brazilian experiences
}

Romeu Gomes ${ }^{1}$

Maria Cecília de Souza Minayo 2

Simone Gonçalves de Assis ${ }^{2}$

Kathie Njaine ${ }^{3}$

Miriam Schenker 4

\footnotetext{
1 Departamento de Ensino, Instituto Fernandes Figueira, Fiocruz. Av. Rui Barbosa 716, Flamengo. 22250-020 Rio de Janeiro RJ. romeu@iff.fiocruz.br

2 Claves, ENSP, Fiocruz.

3 Claves, ENSP,

Fiocruz; Uniplac.

4 Claves, ENSP

Fiocruz; Uerj.
}

\begin{abstract}
The present study analyzes the success of Brazilian experiences engaged in prevention of violence as well as their limitations, and seeks to show ways for a solution of the problem. The investigation underlying this article consisted in a case study of nine experiences, using triangulation of methods. For this purpose, we used questionnaires and interviewed individuals and groups. Successful results were mainly: informed citizenship, work preparation, involvement of children and adolescents in recreating and educative activities, and increased self-esteem of the children and teens involved in the experiences. The greatest difficulties found were the lack of funds and of articulation of proposals with other groups and institutions. These experiences are not the only successful ones carried out in the country, but they point to a new horizon by innovating and creating a different practical approach to violence.
\end{abstract}

Key words Prevention, Violence, Successful experiences
Resumo O presente estudo tem como objetivo analisar os êxitos e os limites de experiências nacionais na prevenção da violência e indicar possibilidades de enfrentamento do problema. A pesquisa que dá origem ao artigo consistiu em um estudo de caso de nove experiências, seguindo princípios da triangulação de métodos. Foram aplicados questionários quantitativos e realizadas entrevistas (individuais e grupais). Os resultados apontam que os principais êxitos relatados são: informação para a cidadania; preparação para o trabalho; envolvimento de crianças e adolescentes em atividades lúdicas e educativas e o fortalecimento da auto-estima dos jovens e crianças participantes. As maiores dificuldades das experiências são a manutenção financeira e a articulação de suas propostas com as de outros grupos e instituições. O estudo leva a concluir que essas experiências, ainda que não sejam as únicas bem-sucedidas no País, apontam para um horizonte novo pela forma como atuam, inovando e criando uma práxis diferenciada na abordagem da violência.

Palavras-chave Prevenção, Violência, Experiências exitosas 


\section{Introdução}

Este estudo se insere no campo das análises de políticas sociais, sejam realizadas pelo Estado, pela iniciativa privada ou por organizações da sociedade civil, que se abriga nas diretrizes da Lei Orgânica da Assistência Social, criada a partir da Constituição de $1988^{1}$. Como se poderá constatar, embora tenham como meta a prevenção da violência, todos as experiências aqui relatadas visam, sobretudo, a aumentar e a incrementar a capacidade das pessoas atendidas de se incluírem nas conquistas sociais brasileiras e de, assim, usufruírem de direitos e assumirem deveres. O intuito do Ministério da Saúde, ao fazer a proposta de avaliação de experiências exitosas voltadas para prevenção de violência contra crianças e jovens, tem os mesmos pressupostos de inclusão e conquista de direitos, uma vez que a filosofia que fundamenta a Política Nacional de Redução de Acidentes e Violências/Ministério da Saúde (MS) de 2001 é a da promoção da saúde e da qualidade de vida. Também em É possível prevenir a violência? Minayo et al. ${ }^{2}$ já haviam trabalhado esse tema, evidenciando que o oposto da violência não é a não-violência; é a conquista da cidadania, que assegura as possibilidades do diálogo e do entendimento. $\mathrm{Na}$ área da saúde, algumas diretrizes importantes vêm sendo seguidas nesse sentido, e algumas delas constam do Plano Nacional de Prevenção da Violência e do Programa de Redução da Morbimortalidade por Acidentes de Trânsito, ambos sediados na Secretaria de Vigilância em Saúde/MS.

A preocupação - que inclui o governo brasileiro e a sociedade - de propor programas sociais inclusivos e de avaliar sua eficácia tem respaldo em atuações reconhecidamente bem-sucedidas de outros países ${ }^{3-6}$.

No entanto, mais do que o Estado, as organizações não-governamentais (ONGs) têm sido, historicamente, pioneiras no oferecimento de serviços de atenção e prevenção à violência, como é o caso dos Crami (Centros Regionais de Atenção aos MausTratos na Infância), em São Paulo; da Abrapia (Associação Brasileira Multiprofissional de Proteção à Infância e à Adolescência), no Rio de Janeiro; da ABNAPI (Associação Brasileira de Prevenção aos Abusos e Negligências na Infância), em Minas Gerais, que tiveram um papel fundamental na elaboração do ECA (Estatuto da Criança e do Adolescente), de 1990, e para o reconhecimento desse grupo social como sujeito de direitos². A partir do ECA, no período dos últimos 15 anos, muitas outras ONGs e entidades privadas se organizaram e vêm contribuindo para pensar mecanismos de crescimento e desenvolvimento social das crianças e adolescentes, o que significa, em última instância, a prevenção da violência. Também algumas instituições acadêmicas vêm desempenhando papel fundamental nessa questão, formando profissionais, prestando assessoria, analisando programas e serviços e criando indicadores de avaliação.

Apesar do dinamismo de muitas das propostas vigentes, existe pouca atenção e sistematização do pensamento e da ação das instituições públicas, privadas e das ONGs voltadas para o tema "prevenção da violência". Em geral, no Brasil, os esforços da área da saúde (tanto públicos como do terceiro setor) têm se direcionado muito mais para a atenção às vítimas de agravos do que para os aspectos positivos que constituem o avesso da violência.

Portanto, considera-se de elevada relevância investigar a atuação de instituições que deliberadamente têm como objetivo prevenir a violência contra crianças e jovens, no Brasil, especialmente no momento em que foi desencadeada a implementação do Plano Nacional de Prevenção da Violência, pelo Ministério da Saúde, e está em fase de implantação a Rede de Núcleos de Prevenção da Violência e Promoção da Saúde, em alguns estados e municípios com elevadas taxas de mortalidade por causas externas. É fundamental conhecer melhor o sentido das ações desenvolvidas, a dinâmica das relações e os resultados das atividades, para que passos futuros possam ser mais bem orientados, tanto pelas próprias instituições como pelos gestores públicos que precisam de instrumentos de inteligência para alocação de recursos. Nesse caso, é a riqueza das especificidades e a coincidência dos propósitos que podem indicar as múltiplas possibilidades de ação.

A partir dessa perspectiva, o presente estudo tem como objetivo analisar os êxitos e os limites de experiências nacionais na prevenção da violência e indicar possibilidades de enfrentamento do problema.

\section{Método}

O estudo que dá origem a este artigo é uma pesquisa sobre a prevenção da violência, aprovada pelo Comitê de Ética em Pesquisa da Escola Nacional de Saúde Pública da Fundação Oswaldo Cruz (ENSP/Fiocruz), realizada em convênio com a Secretaria de Vigilância e Saúde do MS. Para sua elaboração, foi utilizado o método de "estudo de caso"7, visando a compreender a diversidade de experiências de redes, programas, atividades ou projetos (aqui denominados genericamente de 
experiências) no que se refere à prevenção às diversas manifestações de violências cometidas contra crianças e adolescentes, jovens adultos e famílias, visando à sondagem de tendências, estratégias e posturas consideradas exitosas.

Neste artigo serão focalizados apenas os êxitos e os limites das experiências, sobretudo os que tiverem sido obtidos por meio de dados qualitativos, embora na pesquisa que gerou este trabalho tenham sido utilizados questionários dentro da lógica de "triangulação de métodos", entendida como articulação entre múltiplas técnicas, observadores e métodos ${ }^{8,9}$. Algumas informações dos questionários foram consideradas apenas para caracterizar as experiências em geral.

As experiências foram selecionadas com base nas seguintes fontes de consulta: 1) levantamentos nacionais existentes sobre serviços de prevenção à violência, a exemplo do elaborado pela Secretaria Nacional de Segurança Pública ${ }^{10} ; 2$ ) dados do Conselho Nacional dos Direitos da Criança e do Adolescente; 3 ) informações da Agência de Notícias dos Direitos da Infância.

Do ponto de vista qualitativo, foram feitas "entrevistas de grupo" (grupo focal) com técnicos de cada equipe, que fazem o atendimento promovido pela instituição, e entrevista individual com coordenadores (aqui denominados "gestores") e usuários, abordando, principalmente, os seguintes temas: proposta, metodologia e rotina do atendimento; formas de envolvimento dos usuários; indicadores de atendimento bem-sucedido; pontos positivos e negativos da experiência e articulações do serviço com a rede de iniciativas de proteção à criança, ao adolescente, ao jovem adulto e a seus familiares. Trabalhou-se também com "observação de campo". Os registros desta observação não tiveram um tratamento analítico específico. Eles serviram para contextualizar os depoimentos.

Os dados foram analisados a partir do "método de interpretação de sentidos", baseando-se em princípios hermenêuticos-dialéticos para tratamento do contexto, das razões e das lógicas de falas, ações, conjunto de inter-relações; grupos, instituições, conjunturas, dentre outros corpos analíticos ${ }^{11}$. A análise partiu de uma leitura compreensiva e da problematização dos modelos subjacentes às idéias, buscando-se os sentidos das falas de forma contextualizada.

Aos "êxitos e limites", foi dado um tratamento especial, por meio de indicadores qualitativos criados a partir dos depoimentos. Para a análise de indicadores qualitativos, foram cumpridos os seguintes procedimentos, adaptados de Gomes et al. ${ }^{11}$ e Assis et al. ${ }^{12}$ : 1) leitura compreensiva dos depoimentos; 2) recorte de trechos em duas classes: êxitos e limites ou dificuldades; 3 ) identificação dos diferentes sentidos atribuídos a cada classe; 4) reunião dos sentidos encontrados em cada classe em temáticas mais amplas; 5) elaboração de síntese interpretativa dos indicadores.

\section{Caracterização das experiências}

Em toda a pesquisa, foram estudadas as seguintes experiências: 1) Agência Uga-Uga, em Manaus (Norte); 2) Centro de Cultura Negra, em São Luís (Nordeste); 3 ) Movimento de Saúde Mental, em Fortaleza (Nordeste); 4) Programa Sentinela, em Cuiabá (Centro-Oeste); 5) Circo de Todo Mundo, em Belo Horizonte (Sudeste); 6) Luta pela Paz, no Rio de Janeiro (Sudeste); 7) Construção da Paz/Colégio Eduardo Guimarães, no Rio de Janeiro (Sudeste); 8) Centro de Referência às Vítimas de Violência do Instituto Sedes Sapientiae, de São Paulo (Sudeste); 9) Centro Social Marista de Porto Alegre (Sul).

As experiências Uga-Uga, Centro de Cultura Negra, Movimento de Saúde Mental, Circo de Todo Mundo, Luta pela Paz e Construção da Paz são organizações não-governamentais (ONGs); o Centro de Referência às Vítimas de Violência e o Centro Social Marista são fundações ou empresas privadas; e o Programa Sentinela é uma ação do governo municipal. A supremacia das ONGs (seis ao todo) mostra como este setor se antecipou na prevenção da violência nesta fase da vida. Todas as experiências foram iniciadas entre os anos de 1991 e 2002, com exceção do Centro de Cultura Negra, em São Luís (Maranhão), que começou as atividades em 1979.

A Agência Uga-Uga, situada em Manaus (AM), se volta para a prevenção da violência sexual infanto-juvenil, por intermédio da comunicação e da informação, notadamente a mídia escrita e impressa. Compõem essa agência o jornal UgaUga, que visa à "participação" e ao "protagonismo" de adolescentes e jovens que, na sua maioria, cursam o ensino médio; a Escola Cidadã, que utiliza, de forma mais estruturada, a comunicação e a informação como instrumentos de educação na escola; e o Projeto Rede Andi (Agência Nacional dos Direitos da Infância), que tem como público-alvo jornalistas e comunicadores e o propósito de universalizar as informações acerca das questões relacionadas à infância e à adolescência.

O Centro de Cultura Negra (CCN), situado em São Luís (MA), é a primeira entidade do movi- 
mento negro do Maranhão. $\mathrm{O}$ centro visa à formação e à informação da população negra para a superação da situação de violência (discriminação racial) em que vive. Atua em quilombos, intervindo na questão fundiária e da terra e revendo as precárias políticas públicas que são implementadas para essas comunidades. Na cidade, desenvolve, principalmente, projeto com grupo de dança e percussão, como estratégia de captação de pessoas para um trabalho de conscientização e ações educativas e de formação. Atua, também, no reforço escolar com crianças de sete a 13 anos.

O Movimento de Saúde Mental (MSM), localizado em Fortaleza (CE), em um dos seus focos, envolve crianças e adolescentes, por intermédio de atividades lúdicas, visando à promoção da auto-estima. Especificamente para adolescentes, promove cursos profissionalizantes. Famílias também são envolvidas no movimento por meio de terapia comunitária, realizada em grupos que desenvolvem a escuta do problema do outro e o respeito ao mesmo. Em torno de suas ações, promove mobilizações nas escolas, na própria família e nas igrejas, sem distinção de raça, cor, credo ou ideologia.

O Programa Sentinela (PS), situado em Cuiabá (MS), se direciona para o atendimento da criança e do adolescente vitimados, mas também trabalha outros tipos de prevenção. A maior parte do público, hoje em dia, é formada por vítimas de abuso e exploração sexual. O programa coordena um comitê com mais cinco organizações, visando à mobilização, ao esclarecimento e ao entendimento do que é a violência, e também aponta para os serviços a que as pessoas podem recorrer. As crianças e os adolescentes que chegam ao programa são recebidos por uma equipe multidisciplinar, que cobre desde o atendimento individual até as oficinas. Suas ações também envolvem acolhimento à família, visitas domiciliares e contatos com as escolas.

O Circo de Todo Mundo (CTM), situado em Belo Horizonte (MG), tem como foco o trabalho infantil, e, em torno deste, a primeira experiência de um projeto pontual sobre o abuso e a exploração sexual. O Circo trabalha em uma postura de escuta permanente, com crianças e adolescentes que vivem uma história de exclusão: os meninos de rua e os meninos na rua. Instituiu a brincadeira, o lúdico e as atividades artísticas - teatro, argila e pintura - como instrumento pedagógico na discussão da violência. Também desenvolve atividades com a escola e com a família visando, com relação a esta última, à conscientização do papel que os familiares têm na criação dos filhos, tarefa muitas vezes delegada aos profissionais do Circo.
A ONG Luta pela Paz (LP) localiza-se no Complexo da Maré, no Rio de Janeiro, e tem a proposta inicial de oferecer o boxe como esporte de contato com os jovens que moram em uma comunidade mais comprometida com o "uso abusivo de drogas e com a violência urbana armada". Os usuários recebem aulas de cidadania, que são prérequisito para se engajarem nos seguintes esportes: luta livre, boxe e capoeira. Também são oferecidas palestras sobre prevenção e, principalmente, sobre doenças sexualmente transmissíveis - incluindo a Aids - e aborto. Conta com parcerias de algumas empresas que encaminham os jovens para o mercado de trabalho.

A experiência Construção da Paz (CP) é um programa recente de uma escola privada que existe há décadas e tem sede na cidade do Rio de Janeiro. Sua proposta é formar "construtores da paz" por meio de um trabalho que contemple a gestalt do indivíduo, suas relações e inter-relações, com o intuito de sensibilizá-lo a "atuar melhor na sociedade". Essa experiência visa a envolver alunos, pais, professores e a comunidade em geral em ações de assistência e de conscientização sobre a inclusão de portadores de necessidades especiais no contexto escolar. Objetiva sensibilizar a comunidade em relação às diferenças; desenvolver o espírito solidário entre os participantes; propiciar a discussão sobre valores e ética; e fomentar ações de voluntariado entre todos os envolvidos.

O Centro de Referência às Vítimas de Violência (CRVV) é um dos quatro centros que compõem um dos núcleos do Instituto Sedes Sapientiae, localizado em São Paulo (SP). Sua proposta é capacitar funcionários, pais, crianças e adolescentes de uma determinada instituição, localizada em uma região mais desfavorecida, na prevenção à violência, notadamente a "violência doméstica". Dessa forma, a instituição, uma vez capacitada, transforma-se em "pólo de prevenção", tornando-se uma multiplicadora dessas idéias e ações no seu entorno. A capacitação é feita segundo uma metodologia participativa, cujo objetivo final é deixar naquela instituição referências de multiplicadores.

O Centro Social Marista (Cesmar), situado em Porto Alegre (RG), preocupando-se com a questão humana, desenvolve um trabalho de "inclusão e de integração com a família". Com suas ações, busca desenvolver a "auto-estima" de seus alunos que provêm de comunidades de baixa renda. Promove oficinas e aulas de reforço da educação formal. O Centro também atende à demanda comunitária, como a regularização das moradias, impasse atual das comunidades com a prefeitura. 
Promove oficinas visando à formação de "grupos de geração de renda", porque acredita que a família não terá paz, caso não possua nenhuma fonte de renda. Conta com cooperativas familiares de panificação, tecelagem, corte e costura, todas formadas a partir do seu programa, que se configura como possibilidade de diminuição da violência.

A maior parte das experiências atua na "prevenção primária" e, mais especificamente, na "capacitação de profissionais" quanto aos diversos tipos de violência. Esta capacitação visa a desenvolver as habilidades e conhecimentos para lidar com informação e educação e para se relacionar devidamente com as pessoas e seu meio ${ }^{13}$ e para modificar o senso comum a respeito da violência em suas várias modalidades. Três experiências operam no nível "secundário" da prevenção e, para isso, preocupam-se em fazer um diagnóstico e uma intervenção precoce voltada, por exemplo, para a prevenção de atitudes preconceituosas e discriminatórias, uso de drogas, envolvimento com o crime e o tráfico de drogas ${ }^{13}$. Promovem um acolhimento diferenciado e respeitoso dos usuários, visando ao fortalecimento da auto-estima, conjugado a atividades que propiciam oportunidade de melhor integração e reinserção social de crianças e adolescentes atendidos por alguns dos programas. Somente uma das experiências estudadas promove prevenção "terciária", por meio de um atendimento multidisciplinar a vítimas de abuso e exploração sexual.

O foro de prevenção privilegiado para a maioria dos casos - oito no total de nove - é a educação, desenvolvida a partir de atividades em oficinas ou cursos. Somente uma experiência privilegia a escola tradicional como espaço de trabalho preventivo.

A diversidade é visualizada nos seguintes campos de atuação: 1) família: focalizada, com sucesso, por três experiências. Uma quarta busca trabalhar em parceria com os pais, mas sua tentativa tem sido vã até o momento desta pesquisa; 2) trabalho: alvo de quatro delas, por meio de cursos profissionalizantes, parceria com empresas e grupos de geração de renda para contemplar os familiares; 3 ) mídia: contemplada por uma experiência, cujo foco é a capacitação de jornalistas; e 4) comunidade: abordagem de três experiências, por meio de terapia comunitária e de mobilização popular.

As principais ações de prevenção desenvolvidas por todas são: distribuição de material educativo sobre proteção e prevenção à violência e organização de grupos de adolescentes, como pode ser visualizado no gráfico 1 que resume o conjunto de atividades.

No conjunto das experiências estudadas em 2003, foram registrados 14.456 atendimentos (Gráfico 2). Deste total, 11.337 pessoas foram abordadas pela ONG que trabalha com comunicação, fato que a destaca das demais experiências, embora também esteja sujeita a oscilações por causa da incerteza dos financiamentos, como se pode verificar. Excluindo-se esse programa, há uma média de 390 pessoas atendidas por experiência/ano, oscilando-se entre 124 na ONG que lida com esporte e 950, na que coloca seu foco em educação e em atividades comunitárias. Em 2004, o total foi de 7.004 atendimentos para o conjunto dos casos estudados, eviden-

\section{Gráfico 1}

Número de atendimentos realizados pelas experiências exitosas de prevenção à violência - 2003/2004.

Grupo de sala de espera Atividades de esporte e lazer visando à prevenção à violência Palestras

Grupo de crianças Grupo de pais

Visita domiciliar

Entrevistas individuais com familiares Entrevistas individuais com pais Entrevistas individuais com crianças/adolescentes

Atividades de arte, teatro, música Oficinas de prevenção à violência Distribuição de material educativo sobre prevenção à violência Grupo de adolescentes/jovens

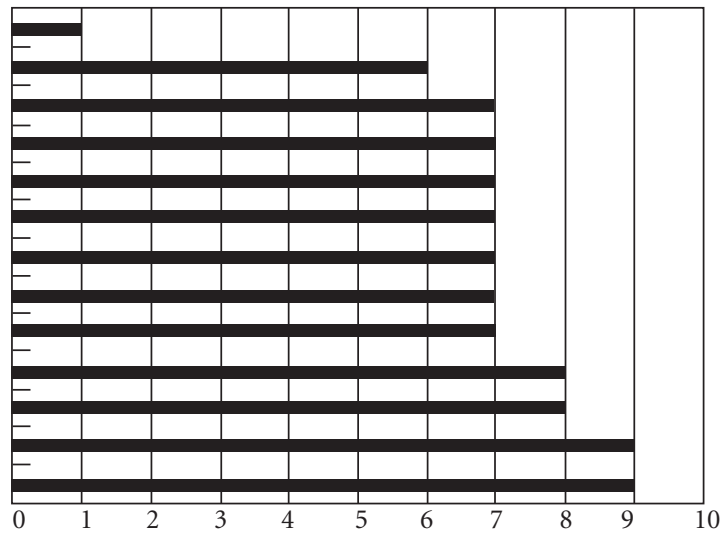


Gráfico 2

Número de atendimentos realizados pelas experiências exitosas de prevenção à violência - 2003/2004 .

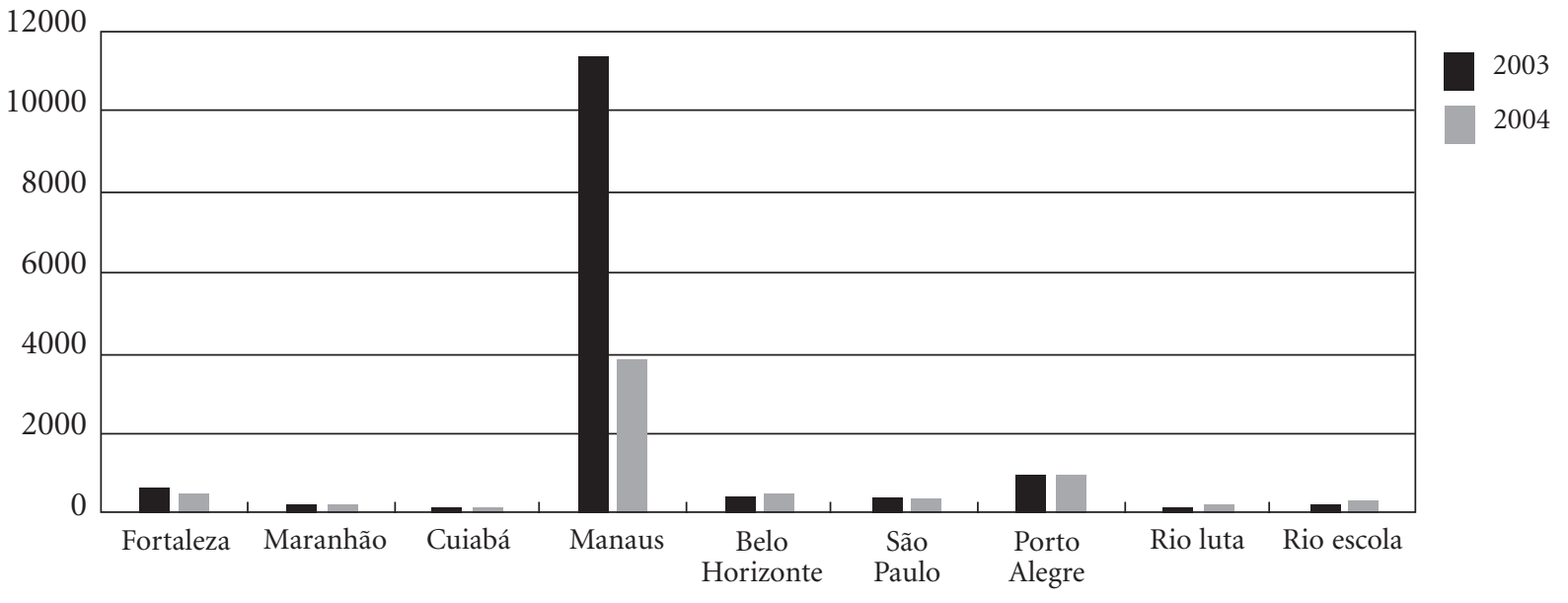

ciando as dificuldades citadas para manter constância nos serviços. Nesse ano, a ONG que trabalha com comunicação se destaca com 3.865 atendimentos. As demais experiências trabalharam com uma média de 392 pessoas, número próximo ao constatado no ano anterior. As mesmas ONGs mantêm o maior e o menor número de participantes, com 210 e 1.000 durante o ano letivo.

Considerando a faixa etária atendida nos anos de 2003 e 2004, constata-se que as instituições privilegiam crianças e jovens de 10 a 19 anos com ações de proteção e prevenção, vindo a seguir o grupo de 7 a 11 anos. Seis experiências atendem jovens de 20 a 24 anos de idade.

Nos anos de 2003 e 2004, duas instituições trabalharam principalmente com o sexo masculino. São as que se dedicam preferencialmente ao esporte e à cultura negra. As demais priorizaram meninas. Um delas atuou de forma equilibrada com os dois sexos.

Os resultados apontados pelos gestores das experiências avaliadas podem ser vistos no gráfico 3. A "elevação da auto-estima" do jovem é o resultado mais relatado pelas instituições, seguido pela "reinserção social" e "redução do trabalho infantil".

\section{Êxitos e limites da prevenção da violência a partir das experiências estudadas}

A análise das experiências consideradas exitosas evidencia sucesso ao longo de um certo tempo, visão de processo e, também, limites na implementação.

"Informações sobre a cidadania" foi um dos principais êxitos apontados por gestores, técnicos e usuários das experiências CCN (MA), CP (RJ), MSM (CE) e PS (MT). Segundo Araújo ${ }^{14}$ e Njaine et al. ${ }^{15}$, na construção da cidadania ou de práticas cidadãs, o acesso à informação e seu uso assumem papel fundamental, uma vez que a conquista de direitos políticos e a implementação de deveres dos cidadãos passam pela livre obtenção desse bem simbólico que é a informação. Algumas expressões foram utilizadas pelos gestores e usuários das experiências para se referir ao sentido de sua ação. A principal delas foi o de "informação sobre direitos e deveres". Gestores, técnicos e usuários envolvidos nos processos consideram que esse conhecimento pode contribuir para a internalização das referências de autonomia, liberdade e crescimento da consciência cidadã. Os depoimentos valorizam a importância do conhecimento sobre direitos e deveres como o patamar básico das relações humanas e da busca da igualdade, o que, na realidade, constitui o cerne da prevenção à violência, quando se sabe que a violência é exatamente o não-reconhecimento do outro em grau de igualdade. Nesse sentido, observa-se que houve êxitos nas experiências já mencionadas, uma vez que seus usuários se consideram mais informados para que os seus direitos não sejam violados.

"Saber viver com a diferença" foi outra idéia atribuída à informação para a cidadania. Como diz um adolescente da experiência CP (RJ): aprendi a lidar com a diferença na convivência com o cole- 
Gráfico 3

Resultado das ações de prevenção realizadas pelas experiências exitosas de prevenção à violência - 2003/2004.

Reduz a possibilidade de a criança/adolescente/jovem consumir drogas Previne a violência na escola Reduz a possibilidade de a criança/adolescente/jovem se envolver em tráfico de drogas Promove cultura de paz entre criança/adolescente/jovem Previne a violência familiar Previne a exploração sexual infanto-juvenil Previne a violência entre crianças/adolescentes/jovens Previne o trabalho infantil Proporciona a reinserção social de criança/adolescente/jovem Proporciona elevação da auto-estima em criança/adolescente/jovem

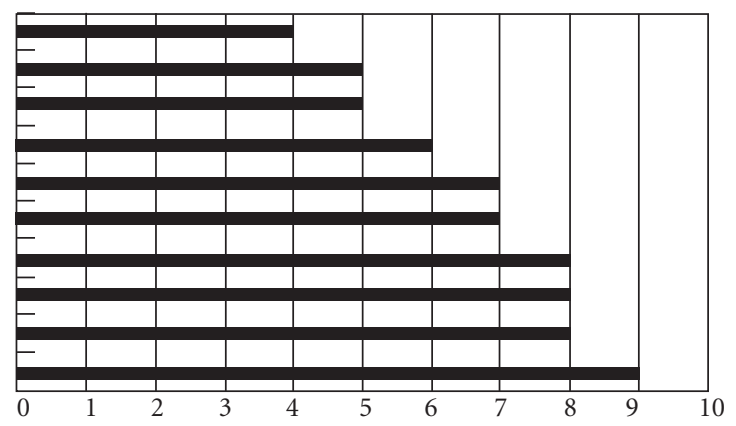

ga homossexual e aprendi a não subestimar jovens com diferenças físicas, pois ele nunca havia imaginado "o tanto que eles podem ser inteligentes". Outro adolescente, que participa do PS (MT), também observa que aprendeu a "encarar as pessoas como elas são [...] e a conviver com pessoas diferentes". Esses depoimentos apontam o êxito do trabalho de informação sobre a convivência com a diferença.

Especificamente em relação ao CCN (MA), subjacentes às falas dos gestores e técnicos, ressaltase a obtenção de resultados no campo da promoção das informações para o exercício da cidadania. Trata-se de promover informações para que crianças, adolescentes e adultos, vítimas reais ou potenciais de violência, visando à sua participação em espaços de representação e de movimentos que defendem os direitos humanos. Esse êxito apontado pelos gestores e técnicos é reforçado pelo depoimento de um de seus adolescentes atendidos, que integra o Conselho de Defesa dos Direitos da População Negra e atua contra a discriminação racial, que ilustra bem esse aspecto: "Eu estou participando também para a militância, fazendo essa luta junto [contra a discriminação racial]".

A literatura internacional menciona a eficácia das atividades que focam a informação bem conduzida sobre direitos e deveres de cidadania. Dentre elas, citam-se programas norte-americanos considerados efetivos que, por meio de visitas familiares, promovem a informação para pais, a fim de que sejam ativos na reivindicação de serviços públicos ${ }^{16}$. Sherman et al. ${ }^{5}$ também consideram a informação como uma das estratégias relevantes para prevenção à violência, ampliando o contexto para outros ambientes. Sugerem a informação também da família, como instrumento de consciência para a busca de apoio social e como instrumento de transformação relacional; na escola pontuam a crucialidade da informação para o desenvolvimento das habilidades e competências individuais e sociais; apontam a comunidade como espaço prioritário onde a informação deve ser fomentada, estimulando a existência de rede de suporte e a comunicação e as ações entre instâncias comunitárias.

"A preparação para o trabalho" também foi apontada como uma ação exitosa nos processos de prevenção da violência, principalmente nos depoimentos de gestores, técnicos e usuários do Cesmar (RS), do CCN (MA) e da LP (RJ). Já desde Marx ${ }^{17}$ e na visão de vários autores recentes como Dubar ${ }^{18}$, o trabalho ocupa um lugar eminente tanto na vida das pessoas como na vida social. Marx dizia que o ser humano, pelo trabalho, transforma a natureza e ao fazê-lo, transforma-se a si mesmo. Dubar focaliza, além dos aspectos de sobrevivência pessoal e social, a referência do trabalho para a formação da identidade dos indivíduos. A privação do trabalho, sobretudo aquele que é reconhecido socialmente, posicionando o sujeito na sua comunidade e no seu mundo existencial, traz sofrimentos íntimos, golpeia a auto-estima, traz comprometimento identitário e é gerador de desorganização social.

Os principais sentidos atribuídos pelos jovens que participam das atividades de qualificação para o trabalho partem de uma negação. $\mathrm{O}$ trabalho é visto como uma espécie de anteparo a algum tipo de desvio possível, exigindo uma reflexão a respeito das possibilidades que os jovens das classes populares têm em relação ao mercado de trabalho e ao sentido positivo das ocupações que conseguem, em relação ao sentido de sua vida. O primeiro tema 
que deles ressalta é a "possibilidade real de serem socialmente menos excluídos". Segundo um adolescente que participa do CCN (MA), ele vivencia atividades que não são proporcionadas em seu colégio, atividades essas que preparam "o jovem para a vida, para encarar o mercado de trabalho".

Outro sentido atribuído à qualificação para o trabalho é o de "evitar a exploração por meio de atividades socialmente consideradas ilícitas". Como diz um adolescente que participa da experiência LP (RJ), "integrando o jovem na sociedade do trabalho, previne também sobre as drogas".

A preparação para o trabalho também é vista como "uma forma de afastamento de uma vida na rua ou de situações de delinqüência". Segundo um jovem da LP (RJ), a experiência de que ele participa dá oportunidade de trabalho para os jovens $e$ [os ajuda a] não estarem se envolvendo na violência armada.

Os gestores e os técnicos do CC (MA) e do MSM (CE) observam que a preparação para o trabalho deve ser promovida junto com a valorização da "educação formal". Assim, as atividades preparatórias voltadas para o trabalho deveriam co-existir com tal educação ou ocorrer após o término da escolarização fundamental.

Em relação ao encaminhamento para o trabalho, estudos têm demonstrado que não há uma relação direta e automática entre as oportunidades de trabalho e emprego e crime e violência ${ }^{5,6,10}$. A análise de programas brasileiros de prevenção à violência com foco no trabalho informa que nem todos apresentam como objetivo a redução da violência, mas, sim, a redução de fatores de risco, como o desemprego e a exclusão social. Por esta razão, esses programas, mesmo que diretamente visem a diminuir índices de violência, representam uma conquista da cidadania da população mais pobre e alijada de muitos bens sociais e um caminho para a promoção de qualidade da vida.

"O envolvimento de crianças e adolescentes em atividade lúdicas e educativas" também foi um êxito apontado, principalmente pelos gestores e técnicos das experiências CCN (MA), CTM (MG), LP (RJ), MSM (CE). As atividades lúdicas envolvem, como observa Brougère ${ }^{19}$, certa cultura de introjeção e a subjetivação de regras oriundas do meio social. A idéia de lúdico como um jogo baseado em regras também foi amplamente estudada por Piaget ${ }^{20}$. Segundo esse autor, o jogo socializado tanto adota regras coletivas como adapta a imaginação simbólica aos dados da realidade.

$\mathrm{Na}$ via da prevenção da violência, diferentes tipos de atividade foram mencionados, como, por exemplo, a dança, o teatro, as brincadeiras tradi- cionais, o esporte e as atividades circenses. Em torno da promoção do lúdico, destaca-se o sentido de "viver melhor a vida" e de "canalização da agressividade". Assim, segundo um gestor que integra a experiência LP (RJ), o esporte hoje está tomando uma dimensão na vida deles [jovens], fazendo com que eles troquem a violência pelo esporte. Já um adolescente do CTM (MG) mencionou que por intermédio das atividades circenses se "recebe a infância de volta". Esta fala remete à idéia de que adolescentes, quando crianças, não tiveram a oportunidade de desenvolver a linguagem lúdica. Com as atividades circenses, eles têm a oportunidade de brincar, o que não puderam fazer quando crianças.

Na literatura, há referência a êxitos de atividades envolvendo recreação como prevenção da violência. Sherman et al. ${ }^{5}$ destacam como promissoras as atividades de recreação para jovens após a escola, quando estes contam com adequada orientação e supervisão, e Abramovay ${ }^{21}$ menciona atividades com êxitos, envolvendo a abertura da escola nos fins de semana com atividades de lazer, acolhendo alunos e suas famílias.

Gonçalves et al. ${ }^{22}$, ao analisarem ações de prevenção da violência escolar promovidas por instituições públicas da cidade de São Paulo, também destacam o sucesso de uma experiência voltada para a recreação, o esporte e o lazer. Trata-se de um programa que, basicamente, consiste na abertura dos portões de uma escola, nos fins de semana, para várias atividades. Segundo os autores, apesar das dificuldades na implementação da proposta, tais atividades contribuíram para "reduzir índices de violência anteriormente observados na escola"22.

"O fortalecimento da auto-estima" é outro êxito presente na fala dos entrevistados, principalmente nos depoimentos dos gestores, técnicos e usuários das experiências CCN (MA), Cesmar (RS), CRVV (SP) e MSM (CE). Foram identificados dois principais sentidos atribuídos ao desenvolvimento da auto-estima. O primeiro deles se refere à "promoção de estímulos" que levam crianças, adolescentes e adultos, a "gostarem de si próprios" a partir do conhecimento de suas potencialidade e limites. Para o gestor do Cesmar (RS), trabalhar com a questão da auto-estima [faz com que] aos poucos [os jovens] se reconheçam mais como pessoa, como alguém de valor, alguém que tem possibilidade. Segundo o gestor do MSM (CE), o trabalho com a auto-estima das pessoas faz com que elas "respeitem a vida dos outros".

Nos sentidos tratados no item anterior, as atividades voltadas para a promoção da auto-estima levam à prevenção primária da violência. 
Pois aprendendo a "gostar de si" as pessoas não se colocam no lugar de vítimas, acostumam-se a lidar com discriminações e com agressões físicas e psicológicas, protegendo-se e fortalecendo-se.

O outro sentido atribuído pelos entrevistados ao trabalho com a auto-estima relaciona-se ao "fortalecimento da capacidade de lidar com a vida", sobretudo em situação de violência. As pessoas que vivenciaram situações de violência recebem estímulos para que possam ressignificar suas vivências negativas e exercitar suas competências ${ }^{23,24}$ para que, assim, não recaiam na vitimização.

O depoimento emocionado de uma senhora que participa da experiência do CRVV (SP), que trabalha com pais, crianças e adolescentes envolvidos na violência doméstica, mostra que ela e o filho conseguiram ressignificar suas vidas e encontrar novos horizontes: Eu era uma pessoa assim totalmente deprimida. Eu não conseguia falar, sabe? Eu não conseguia ver as coisas. Me ajudou muito, tem ajudado muito meu filho, que ele aprendeu a se defender do pai. Se eu não tivesse vindo aqui, procurando um pouco de segurança, de apoio, a minha vida não teria mais sentido, o meu filho não teria nem comando, nem domínio sobre ele.

A discussão sobre a relevância de se trabalhar com a promoção da auto-estima pode ser sustentada a partir de estudos realizados em vários países. A maioria ressalta os bons resultados obtidos por ações preventivas voltadas para a competência emocional e social de escolares, desenvolvimento de habilidades, autocontrole, relacionamento interpessoal e redução de conflitos $6,25,26$.

Um capítulo importante do trabalho de análise das experiências e que constitui o segundo objetivo deste artigo foi o levantamento dos limites e das dificuldades por que passam as instituições para cumprirem seus objetivos. O primeiro deles é o de "conseguir recursos financeiros" para garantir sustentabilidade, continuidade ou, algumas vezes, ampliação das ações exitosas. O segundo, que revela a práxis e as diretrizes de organização do trabalho, diz respeito à "falta de articulação com outros grupos ou instituições". Esses dois limites encontram-se presentes principalmente nos depoimentos dos gestores e dos técnicos da maioria das experiências estudadas.

As dificuldades de dar "sustentabilidade financeira às propostas" foram constatadas mesmo no caso das experiências que possuem mecanismos de captação de recursos para o seu funcionamento. Mas, neste particular, os problemas das ONGs se diferenciam das dificuldades que têm as entidades públicas. A maioria das experiências estudadas faz parte de atividades de ONGs e vive problemas que atingem às instituições desse tipo. Parte do terceiro setor, as ONGs são entidades que atuam na esfera pública não-estatal, constituídas a partir de iniciativas privadas, voluntárias, sem fins lucrativos e voltadas para o bem comum ${ }^{27}$. O funcionamento dessas organizações depende de fundos públicos ou de voluntários, não havendo, em geral, uma obrigatoriedade dos doadores de dar continuidade à sustentação dos projetos. Por sua vez, a multiplicação de ONGs não tem sido seguida de avaliações sistemáticas, o que costuma deixar os doadores inseguros quanto às aplicações de recursos. Alguns estudiosos como Santos et al. ${ }^{28}$ consideram que o terceiro setor continua a ser o menos avaliado dos três que compõem as macro-instituições democráticas (estado-mercado-sociedade civil). Esse fato, além do caráter voluntário de muitas iniciativas sociais, deixa-as totalmente vulneráveis do ponto de vista da sustentabilidade financeira, mesmo quando suas atividades são avaliadas positivamente, principalmente pelas pessoas que elas atendem.

Os depoimentos de vários entrevistados, tanto gestores e técnicos como usuários, no caso das ONGs, ressaltam a insegurança que sentem, sobretudo referida à possibilidade de que faltem recursos para o desenvolvimento das ações no futuro. As falas formam quase que um só coro nesse sentido: as experiências dependem de recursos financeiros públicos para sobreviver, e esses nem sempre são conseguidos a tempo ou na medida da necessidade frente às demandas. Muitos entrevistados se referem à consciência de que assumem tarefas frente às quais o Estado é omisso. Algumas ONGs estudadas possuem uma carteira diversificada com vários tipos de doadores, o que, em parte, diminui a dependência do Estado.

Os entrevistados das experiências que ocorrem em instituições públicas e privadas, principalmente os representantes das coordenações e os técnicos, têm problemas de outra natureza. Embora as atividades sejam mantidas pelas instituições, elas constituem uma espécie de apêndice e não conseguem atingir a dimensão que poderiam adquirir porque sofrem restrições e insuficiências financeiras.

Em geral, na ótica dos gestores e técnicos entrevistados, a inadequação dos recursos financeiros às necessidades das experiências em desenvolvimento tem como conseqüência principal a precariedade das equipes para o atendimento das demandas. Essa precariedade se traduz em termos quantitativos (número insuficiente de pessoas para o atendimento, baixa remuneração de profissionais) e qualitativos (qualificação insuficiente da 
equipe para lidar com a diversidade das atividades e com os diferentes segmentos sociais que as experiências abrangem).

"A falta de articulação com outros grupos e instituições" ficou focalizada nas dificuldades que as instituições que atuam nesse sentido demonstram de conseguir se articular para "inserir os adolescentes no mercado de trabalho". O depoimento de um jovem que participa da experiência do CCN (MA) ilustra esse problema: A gente tem a capacitação, tem a preparação toda, toda aquela parte teórica, prática, mas não [tem] um convênio para a gente ter um estágio garantido.

É claro que o fato de o jovem não conseguir ingressar no mercado de trabalho não se explica, necessariamente, apenas pela falta de uma articulação adequada entre as experiências estudadas e as empresas locais. Segundo Segnini ${ }^{29}$, a estrutura do mercado de trabalho vem sendo influenciada pelo fato de que altas taxas de desemprego são acompanhadas da crescente insegurança e precariedade das novas formas de ocupação. Para a autora, no cenário em que desemprego já não é resultado da ausência de crescimento econômico, mas se tornou inerente ao próprio crescimento econômi$c o$, o avanço do capitalismo brasileiro se expressa, de forma significativa, pelo "registro de profunda heterogeneidade produtiva e desigualdade das relações de trabalho". No entanto, ressaltar essa dificuldade é fundamental, pois ela revela, talvez, pouco investimento nas perspectivas de futuro dos jovens participantes, nos aspectos pragmáticos ansiados por eles.

A "falta de uma adequada articulação com as famílias" também foi mencionada como uma dificuldade para as experiências com crianças e jovens apresentarem resultados positivos. $\mathrm{O}$ depoimento de uma profissional que trabalha no CTM (MG) ilustra essa questão: Existe uma dificuldade ainda muito grande com as familias, o trabalho da família ainda é muito iniciante, mas nós temos buscado parceria.

Estudo realizado pelo Fundo das Nações Unidas para a Infância (Unicef) e pelo Claves ${ }^{30}$ constatou que mesmo para os programas e serviços que se propõem a prevenir a violência contra crianças e adolescentes com a participação das famílias, a transformação das famílias de simples usuárias eventuais em parceiras é um grande desafio. De acordo com esse estudo, os programas de inclusão da família nas atividades de prevenção da violência exigem ampliação e articulação da rede de suporte para que esta se constitua num "sistema de garantia de direitos da criança e do adolescente"30.

Como se pode concluir, as experiências analisadas apresentam mais êxitos do que limitações. As dificuldades que existem em todas não são impeditivas de suas atuações. Ao contrário, são tratadas como desafios para a continuidade, a expansão e o aprimoramento.

\section{Considerações finais}

As experiências, inicialmente referidas como exitosas, a partir da pesquisa de campo, podem ser assim consideradas uma vez que conseguem sucesso em algumas ações que tradicionalmente são consideradas efetivas para a prevenção da violência contra crianças e adolescentes. Assim, com base nos depoimentos dos usuários das experiências, podese considerar o êxito das ações, uma vez que estes relatam elevação da auto-estima; maior preparação para se inserir no mercado de trabalho; maior consciência crítica sobre seus direitos e deveres; e o investimento de tempo e energia em atividades educativas e lúdicas.

Dialogando os êxitos das experiências nacionais estudadas com a literatura internacional sobre programas de prevenção à violência contra crianças e adolescentes, observam-se aspectos comuns entre ambas. Sherman et al. 5 , por exemplo, avaliando mais de 400 programas norteamericanos, consideraram como indicadores de resultado: redução do envolvimento em atos infracionais e violência; menor consumo de álcool e drogas; redução da vitimização; redução de comportamento anti-social, agressivo e do desrespeito a regras sociais; retorno à escola e melhoria do rendimento acadêmico; inserção no mercado de trabalho; no nível individual, maior competência social, auto-controle, fortalecimento de valores morais e consciência crítica e cuidado na relação com os outros e consigo mesmo.

Articulando as experiências brasileiras estudadas com as norte-americanas, constata-se a sintonia entre alguns resultados: preparação para o trabalho, a promoção da auto-estima e do autoconhecimento, o crescente envolvimento das crianças e adolescentes na educação formal. Vale ressaltar, entretanto, que os estudos internacionais têm como enfoque prioritário a "avaliação" quantitativa dos resultados documentados pelos programas. No Brasil, em geral, os programas sociais tendem a ter precárias estatísticas e registros documentais, inviabilizando avaliações epidemiológicas de tal monta.

Estudos para o desenvolvimento de indicadores específicos para avaliar atendimento de prevenção da violência devem ser desenvolvidos. 
Na experiência brasileira, ainda é recente a prática de criar indicadores para analisar qualidade do atendimento. Mesmo no âmbito internacional, pouco se encontra a respeito de indicadores qualitativos. Em geral as avaliações enfatizam a mensuração dos tipos de serviços e dos resultados efetivos, por meio de indicadores quantitativos.

A pesquisa que deu origem a este artigo ressalta, ainda, como pontos problemáticos das experiências a falta de registros institucionais sistemáticos e a ausência da cultura de avaliação das ações, que implica na falta de parâmetros quantitativos e qualitativos que possam indicar impacto na redução da violência.

Do ponto de vista dos limites, ressalta-se a necessidade de investimento, por parte de todas as experiências, na parceria com as famílias, principalmente porque a maioria das entidades trabalha com pessoas em situação de vulnerabilidade. A atuação tendo como foco este grupo precisa compreender as dificuldades que tais famílias enfrentam e dar atenção a esse aspecto para, a partir daí, promover sua participação nas ações típicas das experiências.

A instabilidade ou a precariedade financeira é outro ponto que requer atenção. A interrupção de atividades que envolvem pessoas, sobretudo as que vivem em situação de vulnerabilidade, não danifica apenas a proposta de uma instituição. Acarreta efeitos deletérios para os que participam das atividades e contam com o apoio social dos programas. Por outro lado, há um paradoxo na origem das experiências: as organizações que as propõem, sustentam e não têm fins lucrativos foram criadas a partir da ausência dos poderes públicos frente aos problemas que elas passam a focar e a enfrentar. Sendo, portanto, um projeto voluntário, o proble- ma da sobrevivência das experiências provavelmente estará sempre presente.

As experiências analisadas - ainda que não sejam as únicas bem-sucedidas existentes no País, pois se tratou de uma amostra de conveniência apontam para a consolidação de formas de atuação concretas e inovadoras de prevenção da violência, com ênfase na construção da inclusão na cidadania. Por causa disso, elas precisam ser divulgadas, apoiadas e incorporadas como um patrimônio da cultura brasileira no acervo das políticas públicas, sejam elas do setor de saúde, educação, segurança pública, mídia ou cultura.

Por outro lado, há necessidade de se promoverem pesquisas avaliativas de outras experiências de prevenção à violência, para que se possa refinar indicadores de resultados e comparar êxitos e limites nacional e internacionalmente.

A fragmentação de muitas ações que hoje ocorrem no País em relação à prevenção da violência oblitera os sucessos obtidos solitariamente por alguns programas, isola a possibilidade de compartilhamento de recursos financeiros, humanos, materiais e sociais exigidos para o trabalho de prevenção. As dicotomias entre as iniciativas públicas e privadas e do terceiro setor e entre os modos de trabalho de cada profissão precisam ser superadas paulatinamente. Entretanto, os custos sociais das constantes interrupções de apoio às equipes e às ações de prevenção à violência desgastam e desarticulam importantes trabalhos. Porém, para o bem dos que os usufruem, não paralisam o compromisso social dos profissionais, que tentam suprir as dificuldades, vislumbrando no dia-a-dia, em cada mínimo ganho de seu labor, a esperança de um futuro cidadão para tantas crianças e adolescentes em situação de vulnerabilidade.

\section{Colaboradores}

R Gomes, MCS Minayo, SG Assis, K Njaine e M Schenker participaram igualmente na elaboração deste artigo. 


\section{Referências}

1. Minayo MCS, Fraga PCP, Assis SG, Souza ER, Deslandes SF, Njaine K, et al. Políticas sociais para jovens no Rio de Janeiro: cadastro e análise de casos. Parceria: Claves/Unesco/Fundação Ford/Fundação Ayrton Senna. Rio de Janeiro: Fiocruz; 1999.

2. Minayo MCS, Souza ER. É possível prevenir a violência? Rev C S Col 1999; 4(1):7-32.

3. Banco Mundial. Prevenção comunitária do crime e da violência em áreas urbanas da América Latina: um guia de recursos para municípios. São Paulo: Banco Mundial; 2003.

4. Nuttal C, Goldblatt P, Lewis C. Reducing Offending: an assessment of research on ways of dealing with offending behavior. London: Home Office; 1998.

5. Sherman LW, Gottfredson D, MacKenzie D, Eck J, Reuter P, Bushway S. Prevention crime: what works, what doesn't, what's promising: a report to the United States Congress. Washington: National Institute of Justice; 1997.

6. Thornton TN, Craft CA, Dahlberg LL, Lynch BS, Baer K. Best practices of youth violence prevention: a sourcebook for community action. Atlanta: Center for Disease Control and Prevention, National Center for Injury Prevention and Control, Division of Violence Prevention; 2002.

7. Becker HS. Método de pesquisa em ciências sociais. São Paulo: Hucitec; 1993.

8. Denzin N K. The research act. Chicago: Aldine Publishing Company; 1973.

9. Minayo MCS. Conceito de avaliação por triangulação de métodos. In: Minayo MCS, Assis SG, Souza ER, organizadoras. Avaliação por triangulação de métodos: abordagem de programas sociais. Rio de Janeiro: Fiocruz; 2005. p. 19-51.

10. Mesquita Neto P, Assis SG, Chasin ACM, Daher M, Ricardo CM. Relatório sobre a prevenção do crime e da violência e a promoção da segurança pública no Brasil. Rio de Janeiro: Secretaria Nacional de Segurança Pública (Senasp), Programa das Nações Unidas para o Desenvolvimento (PNUD), Federação das Indústrias do Rio de Janeiro (Firjan); Brasília: Ministério da Justiça/ Projeto Arquitetura Institucional do Sistema Único de Segurança Pública; 2004. [Mimeo].

11. Gomes R, Souza ER, Minayo MCS, Silva CFR. Organização, processamento, análise e interpretação de dados: o desafio da triangulação. In: Minayo MCS, Assis SG, Souza ER, organizadoras. Avaliação por triangulação de métodos: abordagem de programas sociais. Rio de Janeiro: Fiocruz; 2005 p. $185-221$

12. Assis DG, Deslandes SF, Minayo MCS, Santos NC. Definição de objetivos e construção de indicadores visando a triangulação. In: Minayo MCS, Assis SG, Souza ER, organizadoras. Avaliação por triangulação de métodos: abordagem de programas sociais. Rio de Janeiro: Editora Fiocruz; 2005. p. 105-32.

13. Gomes R, Silva CMFP, Njaine K. Prevenção à violência contra a criança e o adolescente sob a ótica da saúde: um estudo bibliográfico. Rev C S Col 1999; 4(1):171-81.

14. Araújo EA. Informação, sociedade e cidadania: gestão da informação no contexto de organizações não-governamentais (ONGs) brasileiras. Ciência da Informação 1999; 8(2):155-67.
15. Njaine K, Souza ER. Informação e comunicação sobre violência: instrumentos para a cidadania. In: Minayo MCS, Souza ER, organizadoras. Violência sob o olhar da saúde: a infrapolítica da contemporaneidade brasileira. Rio de Janeiro: Fiocruz; 2003. p. 269-82.

16. Bilukha O, Hahn RA, Crosby A, Fullilove MT, Liberman A, Moscicki E, et al. The effectiveness of early childhood home visitation in preventing violence. A systematic review. Am J Prev Med 2005; 28(2SI):11-39.

17. Marx K. O capital. Livro I, cap. 6 [inédito]. São Paulo: Ciências Humanas; 1978.

18. Dubar C. A socialização: construção das identidades sociais e profissionais. São Paulo: Martins Fontes; 2005.

19. Brougére G. A criança e a cultura lúdica. In: Kishimoto I, organizador. O Brincar e suas teorias. São Paulo: Pioneira - Thomson Learning; 2002. p. 19-32.

20. Piaget J. A formação do símbolo na criança: imitação, jogo e sonho, imagem e representação. Rio de Janeiro: Zahar; Brasília: INL; 1975.

21. Abramovay M. Escolas inovadoras: experiências bemsucedidas em escolas públicas. Brasília: Unesco, 2003.

22. Gonçalves LAO, Sposito MP. Iniciativas públicas de redução da violência escolar no Brasil. Cad Pesquisa 2002; 115(março):101-38.

23. Assis SG, Avanci JQ. Labirinto de espelhos. a formação da auto-estima na infância e adolescência. Rio de Janeiro: Ed. Fiocruz; 2004.

24. Rosenberg M. Society and the adolescent self-image. Princeton: University Press; 1989.

25. Krug EG, Dahlberg LL, Mercy JA, Zwi AB e Lozano R, editores. Relatório mundial sobre violência e saúde. Genebra: Organização Mundial de Saúde; 2002.

26. Negreiros J. Delinqüências juvenis. Trajectórias, intervenções e prevenção. Lisboa: Editorial Notícias; 2001.

27. Madeira FR, Biancardi MR. O desafio das estatísticas do terceiro setor. São Paulo em Perspectiva 2003; 17(3-4):177-84.

28. Santos BS, Avritzer L. Para ampliar o cânone democrático. In: Santos BS, organizador. Democratizar a democracia: os caminhos da democracia participativa. Rio de Janeiro: Editora Civilização Brasileira; 2002. p. 39-82.

29. Segnini LRP. Educação e trabalho: uma relação tão necessária quanto insuficiente. São Paulo em Perspectiva 2000; 14(2):72-81.

30. Centro Latino-Americano de Estudos sobre Violência e Saúde Jorge Careli/Escola Nacional de Saúde Pública Sergio Arouca/Instituto Fernandes Figueira/Fundação Oswaldo Cruz, Fundo das Nações Unidas para a Infância (Claves/ENSP/IFF/Fiocruz, Unicef). Famílias: parceiras ou usuárias eventuais? Brasília: Claves/ENSP/IFF/Fiocruz, Unicef; 2004.

Artigo apresentado em 3/03/2006

Aprovado em 15/03/2006

Versão final apresentada em 26/04/2006 